\title{
Temperature, season, and latitude influence development-related phenotypes of Philippine Aedes aegypti (Linnaeus): Implications for dengue control amidst global warming
}

Frances Edillo ${ }^{1 *}$, Rhoniel Ryan Ymbong ${ }^{1}$, Alyssa Angel Bolneo ${ }^{1}$, Ric Jacob Hernandez ${ }^{1}$, Bianca Louise Fuentes ${ }^{1}$, Garren Cortes ${ }^{1}$, Joseph Cabrera', Jose Enrico Lazaro ${ }^{2}$ and Anavaj Sakuntabhai ${ }^{3,4}$

\begin{abstract}
Background: Dengue is endemic in the Philippines. Aedes aegypti is the primary vector. This study aimed to determine the hatching behavior and viability of Ae. aegypti first-generation (F1) eggs when exposed to temperature and photoperiod regimes under laboratory conditions.
\end{abstract}

Methods: Parental eggs were collected from selected highland and lowland sites in the Philippine big islands (Luzon, Visayas, and Mindanao) during the wet (2017-2018) and dry (2018) seasons. F1 egg cohorts were exposed separately in environmental chambers at 18,25 , and $38^{\circ} \mathrm{C}$ with respective photoperiods for 6 weeks. Phenotypes (percent pharate larvae [PPL], hatch rates [HRs], and reproductive outputs [ROs]) were determined.

Results: Results of multivariate analyses of variance (MANOVA) between seasons showed significant main effects of temperature, season, and big island on all phenotypes across all sites. Significant interaction effects between seasons on all phenotypes across sites were shown between or among (1) season and big island, (2) season and temperature, (3) big island and temperature, (4) season, big island, and temperature, (5) big island, altitude, and temperature, and (6) season, big island, altitude, and temperature. Factors associated with the big islands might include their ecology, available breeding sites, and day lengths due to latitudinal differences, although they were not measured in the field. MANOVA results within each season on all phenotypes across sites showed (1) significant main effects of big island and temperature, and (2) significant interaction effects between big island and temperature within the wet season and (3) between temperature and photoperiod within the dry season. PPL were highest at $18{ }^{\circ} \mathrm{C}$ and were formed even at $38^{\circ} \mathrm{C}$ in both seasons. Pharate larvae might play an adaptive role in global warming, expanded distribution to highlands, and preponderance to transmit human diseases. HRs in both seasons were highest at $25^{\circ} \mathrm{C}$ and lowest at $38^{\circ} \mathrm{C}$. ROs were highest at $25^{\circ} \mathrm{C}$ in the wet season and at $18^{\circ} \mathrm{C}$ in the dry season.

Conclusions: Temperature and latitude of Philippine big islands influenced the development-related phenotypes of Ae. aegypti in both seasons. The two seasons influenced the phenotypes and their interaction effects with big island and/or temperature and/or altitude. Recommendations include year-round enhanced $4 \mathrm{~S}$ control strategies for mosquito vectors and water pipeline installation in rural highlands.

*Correspondence: feedillo@usc.edu.ph

${ }^{1}$ Mosquito Research Laboratory, Biology Department, University of San

Carlos-Talamban Campus, Cebu City, Philippines

Full list of author information is available at the end of the article original author(s) and the source, provide a link to the Creative Commons licence, and indicate if changes were made. The images or other third party material in this article are included in the article's Creative Commons licence, unless indicated otherwise in a credit line to the material. If material is not included in the article's Creative Commons licence and your intended use is not permitted by statutory regulation or exceeds the permitted use, you will need to obtain permission directly from the copyright holder. To view a copy of this licence, visit http://creativecommons.org/licenses/by/4.0/. The Creative Commons Public Domain Dedication waiver (http://creativeco mmons.org/publicdomain/zero/1.0/) applies to the data made available in this article, unless otherwise stated in a credit line to the data. 
Keywords: Aedes aegypti, Dengue, Development-related phenotype, Global warming, Pharate larvae, Hatching rate, Reproductive output

\section{Background}

Aedes aegypti (Linnaeus), a mosquito vector of dengue, Zika, and chikungunya viruses, occurs widely in the tropics and subtropics. Climate change affects mosquito survival, dispersion, and dengue transmission rates [1]. The macroclimate determines the global range limit of this species, and much of its range in temperate and subtropical regions is sustained by artificial environments [2]. This implies that if domestic environments are available in newly suitable areas, the distribution of Ae. aegypti may expand considerably in the near future. In Asia, the Philippines has ranked first in the number of dengue deaths (63), with a total of 17,630 cases as of March 27, 2021 [3]. Direct medical costs of dengue cases amounted to $\$ 345$ million (in 2012 US dollars) [4]. Dengue outbreaks occurred in temperate regions such as Tokyo, Japan, in 2014, where local transmission by Ae. albopictus was recorded after 70 years without confirmed cases [5]; in Madeira, Portugal, with its first dengue epidemic (2187 reported cases) in 2012 by Ae. aegypti [6]; and in Baguio city, Philippines, with an increase of over 344\% from 385 cases in 2014 to 1710 cases in 2015 [7]. The mosquito's adaptive behaviors support the prevailing view that a future warmer climate will lead to larger mosquito populations and an increase in dengue transmission $[8,9]$. An expanded distribution of Ae. aegypti to a previously nonendemic and mountainous region calls for urgent actions to protect public health [10].

Dormancy is an adaptive mechanism that allows some species to withstand harsh environmental conditions through diapause and quiescence [11, 12]. Diapause is genetically programmed, neurohormone-mediated, and the primary mechanism for survival as shown by $A e$. albopictus and Culex pipiens in environments with seasonal change. Quiescence is an irregular dormancy with slowed metabolism resulting from unfavorable environmental conditions that impede larval hatching [13], but is neither a previously programmed event nor hormonally controlled [14]. Developmental arrest is temporary and is immediately reversible. Aedes aegypti has been reported to undergo embryonic quiescence but several studies have erroneously reported it as diapause $[15,16]$. Diminishing expression of genes associated with lipid storage over time during diapause in Ae. albopictus primarily distinguishes between early diapause and quiescence, and this is likely to reflect a physiological convergence of diapause towards quiescence [11]. Moreover, identifying adaptive genes and genetic loci linked to these genes is the first step towards understanding the mechanisms that enable mosquitoes to survive under ecological conditions influenced by global warming. Elucidating the mechanisms that enable them to persist through challenging ecological conditions provides insights that can help predict population dynamics, the trajectory of population expansion, and the occurrence of dengue outbreaks.

Various vector and health-control interventions have resulted in temporary interruptions of disease transmission and have helped reduce the dengue burden. The enhanced $4 S$ strategy of the Philippine Department of Health (DOH) has been the main focus for dengue prevention and control, where " $4 S$ " stands for the following: (1) seek and destroy mosquito-breeding sites, (2) seek early consultation if one develops dengue-associated symptoms, (3) employ self-protection measures such as wearing long pants and long-sleeved shirts, and (4) say "no" to indiscriminate fogging, and implement fogging only during outbreaks in hotspot areas [17]. We hypothesized that temperature, season, and latitudinal differences as influenced by photoperiod and altitude might play a role in the development-related phenotypes of Ae. aegypti eggs. This study aimed to assess the hatching behavior and viability of Ae. aegypti eggs (first-generation, F1) whose parental eggs were collected from selected highland and lowland sites in the country's big islands (Luzon, Visayas, and Mindanao) during the wet (2017-2018) and dry (2018) seasons, and which had been exposed separately to different temperature and photoperiod regimes under laboratory conditions.

\section{Methods \\ Study sites}

We established a two-site category in each Philippine big island, namely lowlands for study sites $<100 \mathrm{~m}$ above sea level (m ASL) and highlands for sites $>350 \mathrm{~m}$ ASL, considering different ecological topologies across big islands and logistics for mosquito collections. Highland and lowland study sites were selected in each of the Philippine big islands (Fig. 1), with three sub-sites per site, which were located between 0.5 and $3 \mathrm{~km}$ apart (Table 1). Highland sites in Luzon, Visayas, and Mindanao included Baguio city (BG); barangays (the smallest government unit) in Cebu city (CC) mountains; and Maramag, Bukidnon (BUK), respectively. Lowland sites included Quezon city (QC); Liloan (LIL), Cebu; and Cagayan de Oro city (CDO), respectively. These sites were chosen based on (1) elevation, (2) range of latitudes represented by the 


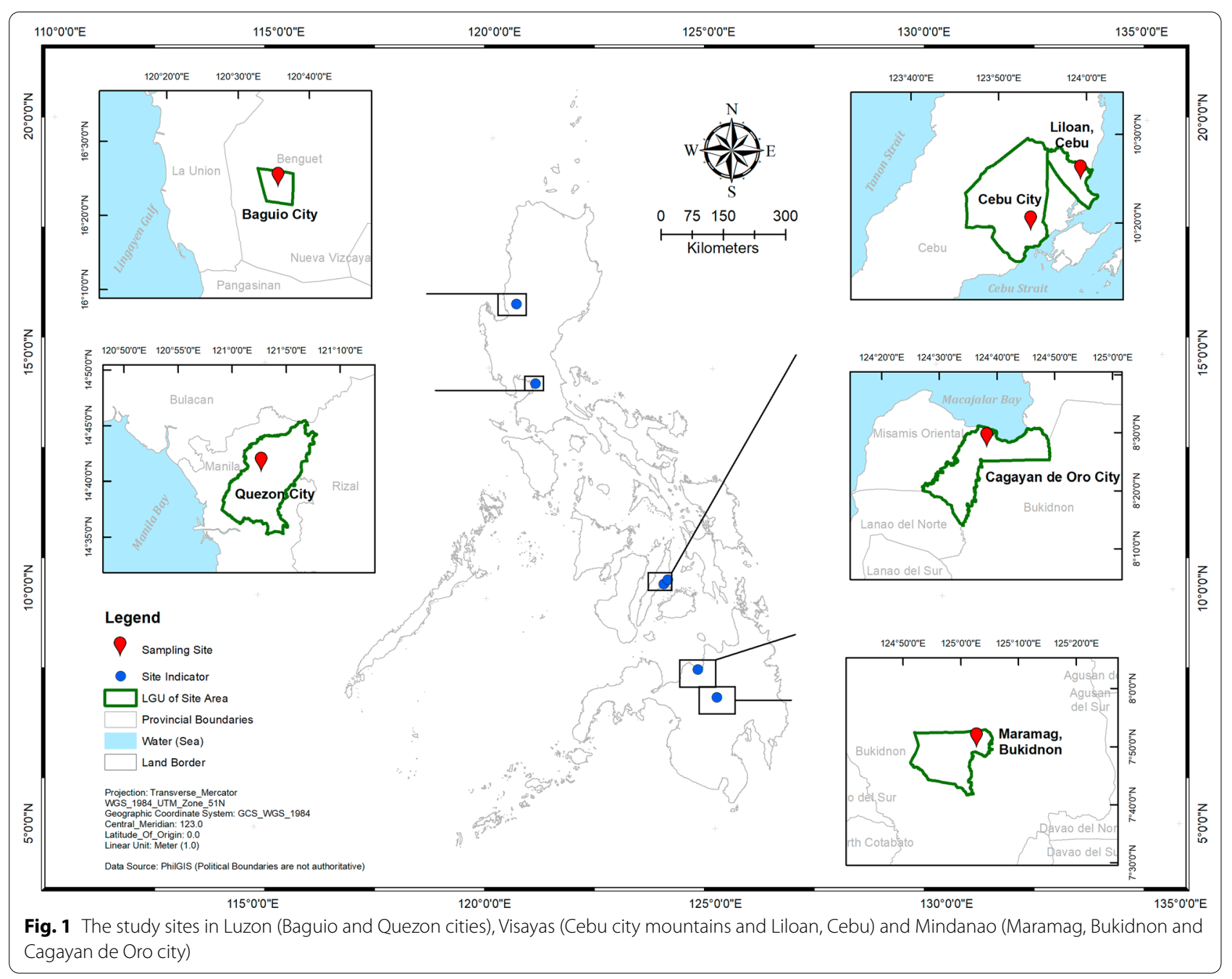

big islands, (3) dengue incidence, and (4) similar biotype according to modified Corona's climate classification [18]. The country has a tropical climate characterized by two seasons, a relatively wet season (June to February) and a dry season (March to May) with longer days and short nights; summer solstice occurs in late June. Meteorological conditions of study sites were taken from the nearest station of the Philippine Atmospheric, Geophysical, and Astronomical Services Administration (PAGASA) and from AccuWeather [19, 20] for Liloan, Cebu (Fig. 2).

\section{Mosquito collections}

Aedes parental eggs were collected using a modified black plastic ovicidal/larvicidal $(\mathrm{O} / \mathrm{L})$ trap or ovitrap (Department of Science and Technology, Manila) method for Mindanao and Luzon sites. Larvae and pupae were collected by a net method [21] from breeding sites in Visayas sites during the wet season (2017-2018); parental eggs were collected by a modified $\mathrm{O} / \mathrm{L}$ trap method in the dry season (2018). Briefly, the O/L trap consisted of a filter paper-wrapped wooden paddle put diagonally inside a black plastic tumbler filled with tap water; the filter paper served as a substrate for female Aedes to lay eggs on. Thirty to $40 \mathrm{O} / \mathrm{L}$ traps were placed randomly outside human dwellings under the roof gutters in each sub-site, and were inspected daily for possible oviposition of Aedes eggs on the filter paper (henceforth called "egg paper"). Each egg paper was air-dried and put inside a plastic cup for shipment, with permission from the Philippine Bureau of Quarantine, Cebu city.

\section{Rearing and coupling of Ae. aegypti for F1 egg cohort collections}

Parental Aedes eggs, larvae, and pupae were reared in the insectary at $23-25{ }^{\circ} \mathrm{C}, 75-80 \%$ relative humidity $(\mathrm{RH})$, and respective photoperiods described below for different experiments. Parental eggs were placed in plastic transparent cups and were submerged in an ascorbic 
Table 1 Philippine highland and lowland study sites in Luzon, Visayas, and Mindanao with coordinates, sub-sites, and their elevations with a sample size of Ae. aegypti F1 egg cohorts per season

\begin{tabular}{|c|c|c|c|c|}
\hline \multirow[t]{2}{*}{ Sites } & \multirow[t]{2}{*}{ Coordinates } & \multirow[t]{2}{*}{ Sub-sites (elevation m ASL ${ }^{a}$ ) } & \multicolumn{2}{|c|}{ Sample size season } \\
\hline & & & Wet & Dry \\
\hline \multicolumn{5}{|l|}{ Luzon } \\
\hline \multirow[t]{3}{*}{ Baguio city (BG) } & $16.402^{\circ} \mathrm{N} ; 120.596^{\circ} \mathrm{E}$ & A. UP-Baguiob (1489) & 90 & 12 \\
\hline & & B. Trancoville (1417) & 78 & 12 \\
\hline & & C. Cabinet Hill (1474) & 76 & 12 \\
\hline \multirow[t]{3}{*}{ Quezon city (QC) } & $14.676^{\circ} \mathrm{N} ; 121.044^{\circ} \mathrm{E}$ & A. NIMBB, UPD ${ }^{c}(75)$ & 89 & 12 \\
\hline & & B. Daan Tubo (65) & 90 & 12 \\
\hline & & C. Payatas B (62) & 90 & 12 \\
\hline \multicolumn{5}{|l|}{ Visayas } \\
\hline \multirow[t]{3}{*}{ Cebu city mountains (CC) } & $10.317^{\circ} \mathrm{N} ; 123.891^{\circ} \mathrm{E}$ & A. Taptap (662) & 90 & 12 \\
\hline & & B. Babag 2 (405) & 90 & 12 \\
\hline & & C. Tabunan, Cantipla (873) & 90 & 12 \\
\hline \multirow[t]{3}{*}{ Liloan, Cebu (LIL) } & $10.4121^{\circ} \mathrm{N} ; 123.986^{\circ} \mathrm{E}$ & A. Poblacion (17) & 90 & 12 \\
\hline & & B. Yati (21) & 90 & 12 \\
\hline & & C. Catarman (16) & 90 & 12 \\
\hline \multicolumn{5}{|l|}{ Mindanao } \\
\hline \multirow[t]{3}{*}{ Maramag, Bukidnon (BUK) } & $7.8592^{\circ} \mathrm{N} ; 125.0515^{\circ} \mathrm{E}$ & A. Lumbo (458) & 90 & 12 \\
\hline & & B. Sentro, Dologon (371) & 90 & 12 \\
\hline & & C. Musuan, Dologon (386) & 90 & 12 \\
\hline \multirow[t]{3}{*}{ Cagayan de Oro city (CDO) } & $8.454^{\circ} \mathrm{N} ; 124.632^{\circ} \mathrm{E}$ & A. Gusa (14) & 90 & 12 \\
\hline & & B. Cugman (21) & 90 & 12 \\
\hline & & C. Bugo (20) & 90 & 12 \\
\hline
\end{tabular}

${ }^{\text {a }}$ Meters above sea level

${ }^{\mathrm{b}}$ University of the Philippines-Baguio

${ }^{\mathrm{c}}$ National Institute of Molecular Biology and Biotechnology, University of the Philippines-Diliman

acid solution (100 mg of ascorbic acid per liter of distilled water [DW]) for 3 days, which facilitated rapid egg hatching via deoxygenation of the water [22]. Emerged larvae were segregated into several plastic cups $(<100$ larvae per cup) containing DW and covered with fine-mesh cloth. The larvae were fed daily with powdered fish food (Sakura; All Aquariums Co., Ltd. Bangkok, Thailand); water was replaced every other day or as needed to prevent accumulation of bacterial scum. Adult mosquitoes were then sorted out by sex and species after eclosion because sometimes $A e$. albopictus samples were present. Male and female Ae. aegypti collected from the same subsite and sampling date were coupled by placing them in a fine-mesh cloth-covered plastic cup with a filter paper at its bottom.

Single mosquitoes were placed in similar cups as a replacement whenever a partner in a couple died. A cotton ball soaked in $10 \%$ sucrose solution was put on top of the fine-mesh cloth. Mosquito couples were allowed to mate over 3-5 days. The mated females were then starved for $24 \mathrm{~h}$, then fed chicken blood mixed with ethylenediaminetetraacetic acid (EDTA) as anticoagulant using a plastic bottle, in which the chicken blood was placed on its bottom depression and sealed with parafilm membrane. The plastic bottle was placed in upright position on top of the mosquito cups covered with fine-mesh cloth with starved couples. Lukewarm water was frequently added inside the plastic bottle to simulate body heat and to attract the females to suck blood. This blood-feeding method is modified from that of Costa-da-Silva et al. [23] to artificially feed Ae. aegypti with blood. After feeding, a cotton ball soaked with $10 \%$ sucrose solution was again placed on the mesh cloth, and the filter paper at the bottom of the mosquito cup was moistened with DW for the female to lay fertilized eggs [24] 2-5 days later. Each dried egg paper was stored inside a parafilm-sealed plastic cup and put inside a dark cabinet for 1.75-2 months, the conventional storage period for Ae. aegypti eggs at $80 \%$ hatch rate (HR) $[25,26]$. At least 30 morphologically viable eggs from each F1 egg cohort were examined under a light microscope. Viable eggs were smooth, shiny black, ovoid-shaped, and $1 \mathrm{~mm}$ long [27], whereas nonviable ones appeared deflated, cracked, or folded. 
a

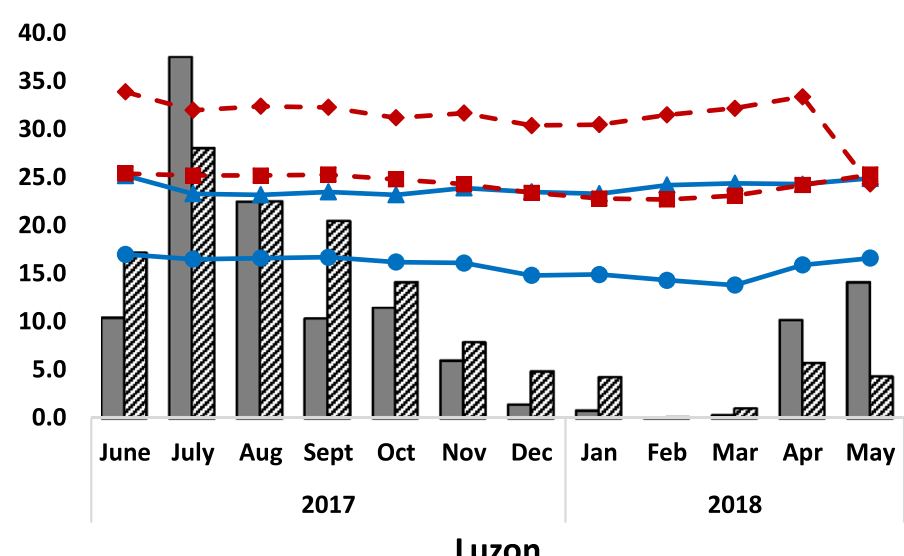

b

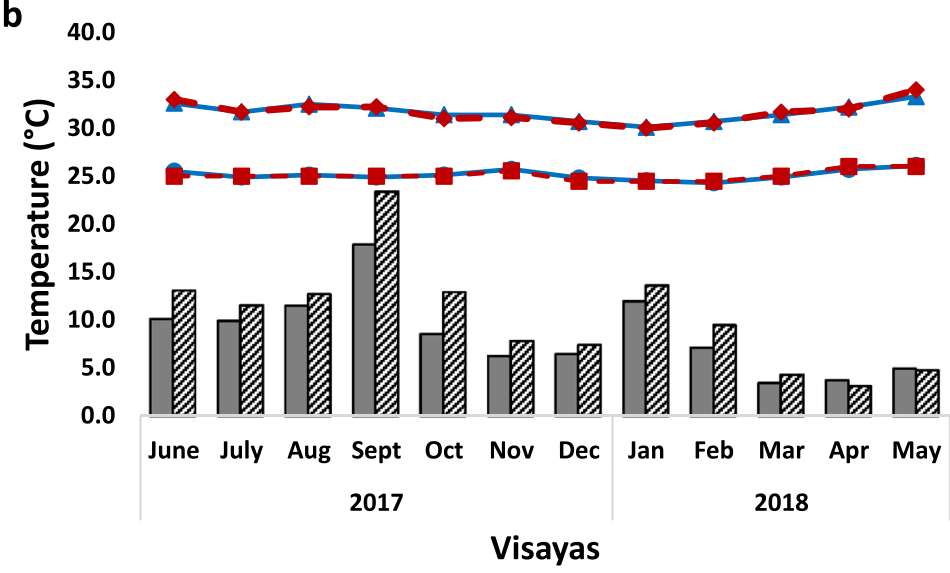

C

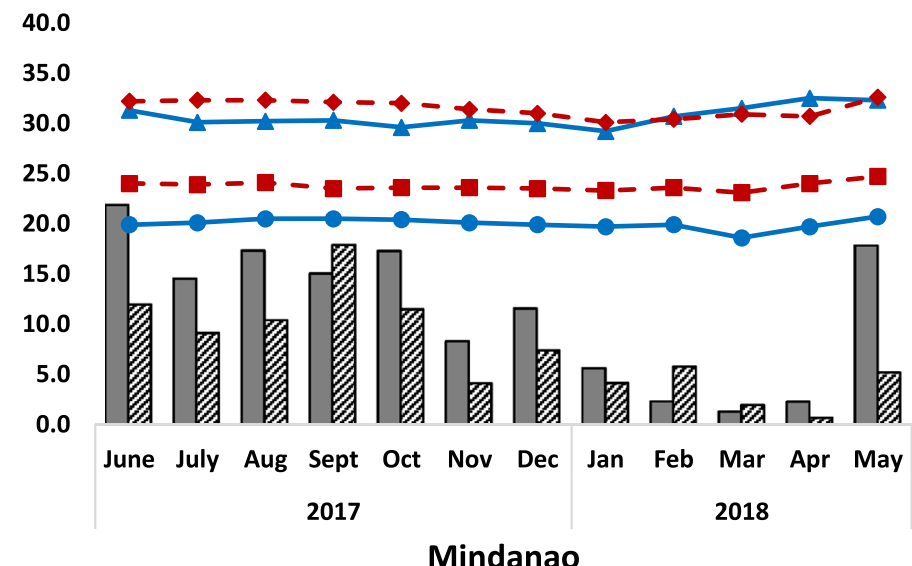

800.0

700.0

600.0

500.0

400.0

300.0

200.0

100.0

0.0

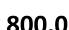

700.0

600.0

500.0

400.0

300.0

200.0 ल

100.0

0.0

800.0

700.0

600.0

500.0

400.0

300.0

200.0

100.0

0.0 $\square$ Baguio city Rainfall

Wuezon city Rainfall

$\longrightarrow$ Baguio city Min Temp

$\longrightarrow$ Baguio city Max Temp

- - Quezon city Min Temp

$-\diamond-$ Quezon city MaxTemp

Mean Min. Temp. $20.7^{\circ} \mathrm{C}$

Mean Max. Temp. $27.6^{\circ} \mathrm{C}$

Mean Rainfall $213.1 \mathrm{~mm}$

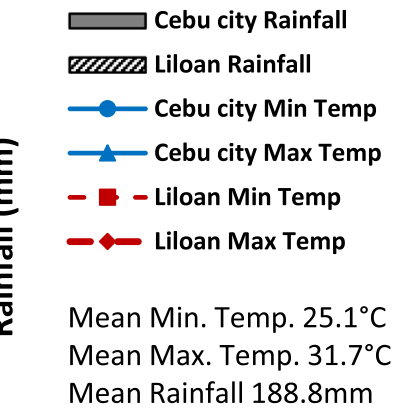

Bukidnon Rainfall WIIX CDO city Rainfall

- Bukidnon Min Temp

$\longrightarrow$ Bukidnon Max temp

- - CDO city Min Temp

$-\downarrow-$ CDO city Max Temp

Mean Min. Temp. $21.9^{\circ} \mathrm{C}$

Mean Max. Temp. $31.1^{\circ} \mathrm{C}$

Mean Rainfall $189.1 \mathrm{~mm}$

Fig. 2 Monthly temperatures (minimum and maximum, ${ }^{\circ} \mathrm{C}$ ) and monthly rainfall $(\mathrm{mm})$ for Baguio and Quezon cities (a), Cebu city mountains and Liloan, Cebu (b), and Bukidnon and Cagayan de Oro city (c) from June 2017 until May 2018

Experimental design for wet season-collected Ae. aegypti Collected parental eggs of Ae. aegypti were reared up to adulthood inside the insectary under 12L:12D photoperiod. F1 egg cohorts from the parental generation were individually placed in loosely covered Falcon tubes, which were then exposed separately to regulated temperature regimes $\left(18,25\right.$, and $\left.38{ }^{\circ} \mathrm{C}\right)$ inside their respective environmental chambers (BPIT-407GC model; BP Integrated Technologies Inc., Laguna, Philippines) with RH of $65-75 \%$ [28] and photoperiod of $8.5 \mathrm{~L}: 15.5 \mathrm{D}$ at $225-745 \mathrm{~lx}$ for 6 weeks. The photoperiod served to simulate the estimated average number of hours that eggs 
in different artificial containers were exposed to daylight in the sites during the wet season. Temperature regimes $\left(18,25\right.$, and $\left.38{ }^{\circ} \mathrm{C}\right)$ were based on approximate average cold $\left(18{ }^{\circ} \mathrm{C}\right)$ and extreme hot temperature $\left(38{ }^{\circ} \mathrm{C}\right)$ with average optimum $\left(25^{\circ} \mathrm{C}\right)$ as control based on seasonal months of PAGASA (2017) readings nearest to the sites. A completely randomized design (CRD) was employed; F1 egg cohorts were randomly selected for experimental treatment (i.e., induction of quiescence) of separate temperature regimes (Fig. 3). These environmental chambers were monitored twice daily to ensure their respective conditions throughout the experimental period.

The required sample size for F1 egg cohorts $(n=540$; i.e., 90 egg cohorts from each site with $\sim 30$ egg cohorts from each sub-site per temperature regime per season) exposed separately to each temperature regime in an environmental chamber (Bio-Integrated Philippines Inc., Manila) was calculated using G*Power sample size software to provide a statistical power of $80 \%$ to detect significant differences in their phenotypes given two altitudes from each big island and three temperature regimes (Table 1) [29].

The F1 egg cohorts were then treated with ascorbate medium (100 mg of ascorbic acid per $1000 \mathrm{ml}$ of DW) inside their respective chambers for 3 days in order to deoxygenate the water and to suppress egg dormancy. Then, they were treated with sodium hypochlorite $(\mathrm{NaOCl})$ solution $(50 \%)$ at room temperature and observed under a compound light microscope attached to a monitor to determine the number of unhatched embryonated eggs (i.e., pharate larvae) and unhatched incomplete embryos [22, 30,31]. The presence of a pair of ocelli, egg burster, and abdominal segments of the unhatched embryonated eggs served as indicators of complete embryogenesis, and hence pharate larvae [31]. The phenotypes included percent pharate larvae (PPL); reproductive output (RO), calculated as the number of F1 egg cohorts that produced surviving larvae; and hatch rate (HR), determined with the following formula [22]:

$$
\mathrm{HR}=\frac{\text { hatched eggs }}{(\text { embryonated unhatched eggs }+ \text { hatched eggs })} \times 100 .
$$

\section{Experimental design for dry season-collected Ae. aegypti}

Rearing conditions for parental adults collected in the dry season were the same as for those in the wet season. However, there were two groups of samples exposed to photoperiods at 12L:12D (control) and 13.5L:10.5D (experimental) (Fig. 4) based on the average day lengths in the wet and dry seasons, respectively, of PAGASA (2017) records nearest the study sites. Four F1 egg cohorts (each with $\sim 30$ morphologically viable eggs on a filter paper) of dry seasoncollected parental eggs from each sub-site for each photoperiod (control at $8.5 \mathrm{~L}: 15.5 \mathrm{D}$; experimental at 12L:12D) were separately exposed at $18{ }^{\circ} \mathrm{C}, 25^{\circ} \mathrm{C}$ (control), and $38{ }^{\circ} \mathrm{C}(n=72$ egg cohorts at each temperature and photoperiod) inside environmental chambers for 6 weeks employing CRD (Fig. 5). The experimental photoperiod served to simulate the estimated average

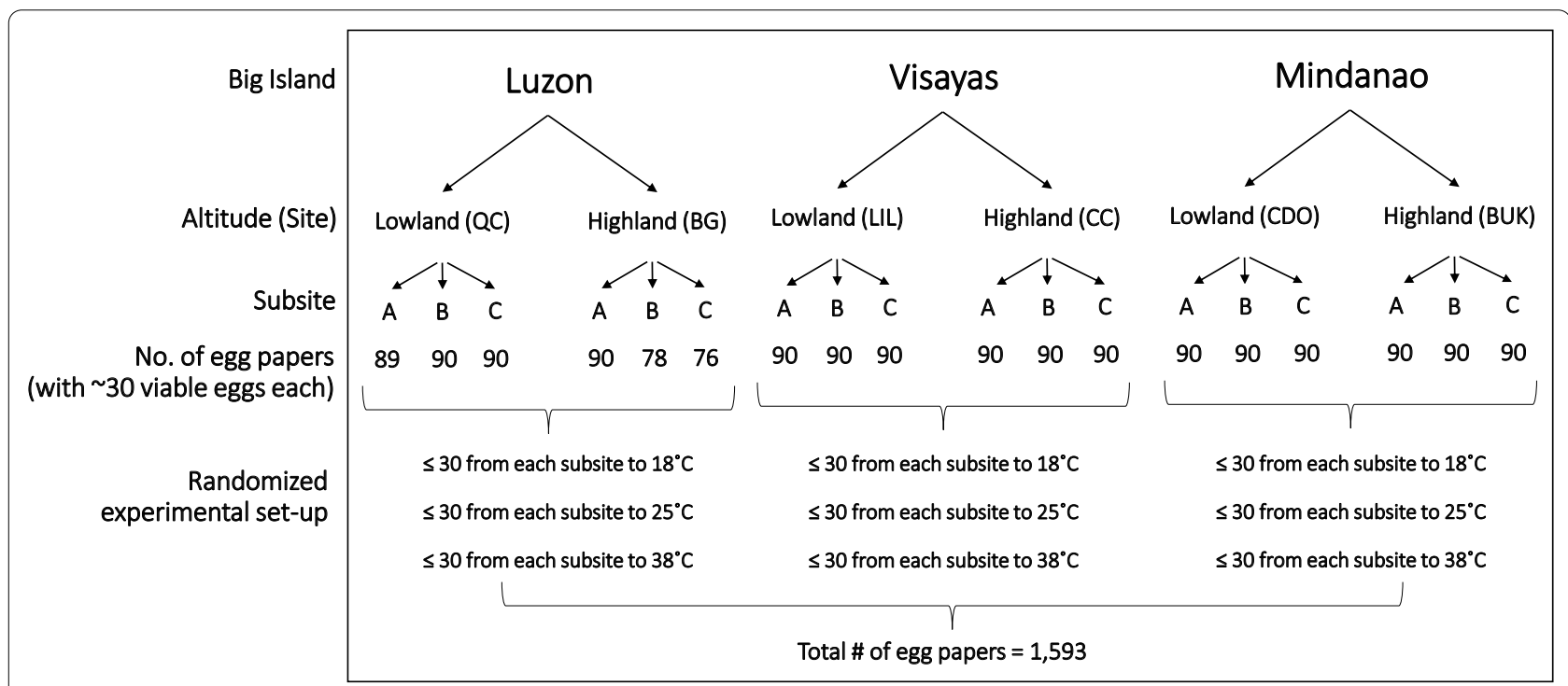

Fig. 3 Flowchart summarizing the randomized experimental setup for the wet season Ae. aegypti F1 egg papers. Sub-sites for lowland and highland sites are listed in Table 1 

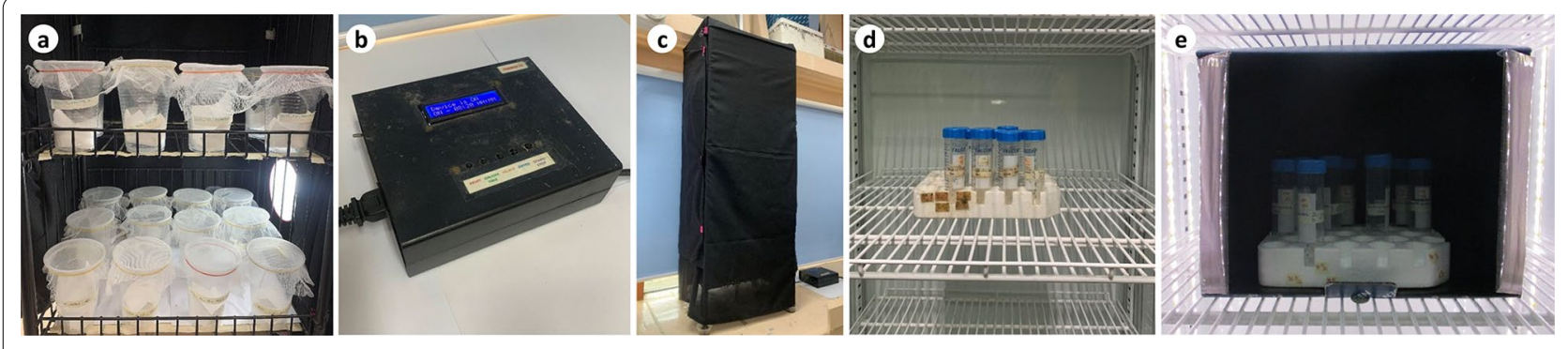

Fig. 4 a-e Photoperiod setup. Adult Ae. aegypti couples inside plastic cups covered with fine-mesh cloth were exposed at 13.5L:10.5D with the use of a lamp a programmed by a timer (b), within a rack covered with a black cloth $(\mathbf{a}, \mathbf{c})$ inside the insectary. F1 Ae. aegypti egg cohorts were exposed inside an environmental chamber programmed at a temperature regime, 65-75\% RH, 8.5L:15.5D (control) (d) and 12L:12D photoperiod (e)

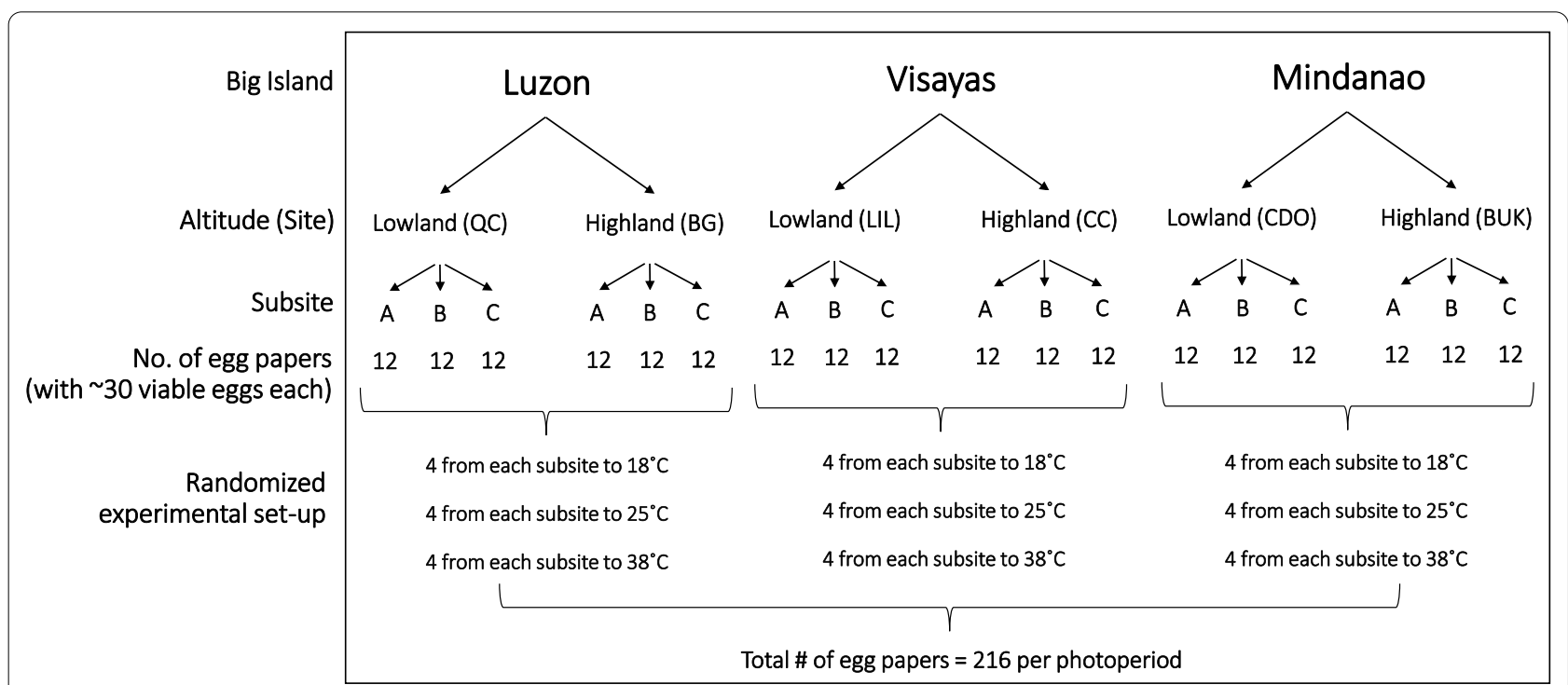

Fig. 5 Flowchart summarizing the randomized experimental setup for the dry season Ae. aegypti F1 egg papers. Sub-sites for lowland and highland sites are listed in Table 1

number of hours that eggs in different artificial containers were exposed to light in the study sites during the dry season. The required sample size for F1 egg cohorts was calculated using G*Power sample size software to provide a statistical power of $83 \%$ in order to detect significant differences in PPL, HRs, and ROs given two altitudes from each big island and three temperature regimes (Table 1) [29]. The F1 egg cohorts were then hatched following the same hatching protocol for parental eggs but without the drying-rehatching step. The egg papers were examined under the microscope to count the larvae 3 days after the eggs hatched, after which the unhatched eggs were bleached using $30 \% \mathrm{NaOCl}$ solution to expose the pharate larvae. The number of hatched eggs and pharate larvae were recorded for each egg cohort. HRs, PPL, and ROs were calculated.

\section{Statistical analyses}

Data sets for dependent variables (PPL, HRs, and ROs) for both seasons were subjected to full-factorial multivariate analyses of variance (MANOVA) using a generalized linear model (GLM) in order to determine the main and interaction effects of independent variables (i.e., altitude, big island, temperature, photoperiod and/ or season) on each dependent variable (PPL, HR, and $\mathrm{RO})$ within and between seasons. Univariate analyses were done after MANOVA's significant interaction effects, then Tukey's post hoc tests followed. 


\section{Results}

This is the first study on the development-related phenotypes of tropical Ae. aegypti collected from different altitudes across the Philippine big islands with latitudinal differences (Luzon at $14.6^{\circ} \mathrm{N}-16.4^{\circ} \mathrm{N}$, Visayas at $10^{\circ} \mathrm{N}$, and Mindanao at $8^{\circ} \mathrm{N}$ ) (Table 1 ).

\section{Development-related phenotypes of wet season-collected Ae. aegypti}

Figure 6 shows the morphological features diagnostic of pharate larvae inside the chorion, which include egg burster, a pair of ocelli, and abdominal segments $(\mathrm{a}, \mathrm{b})$, consistent with temperate Ae. albopictus and Ae. aegypti $[22,31]$ and the incompletely embryonated eggs that are

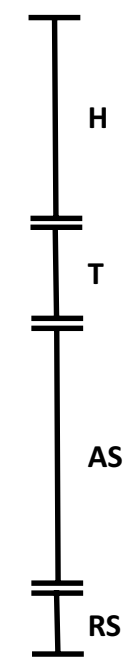

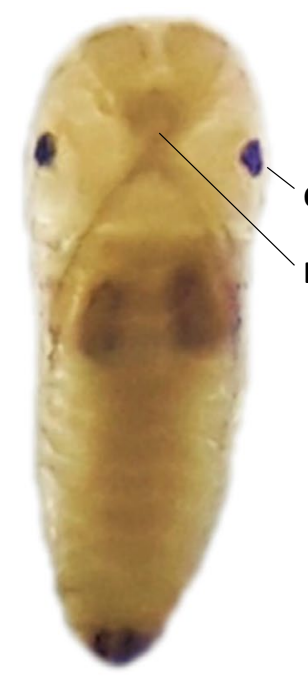

a

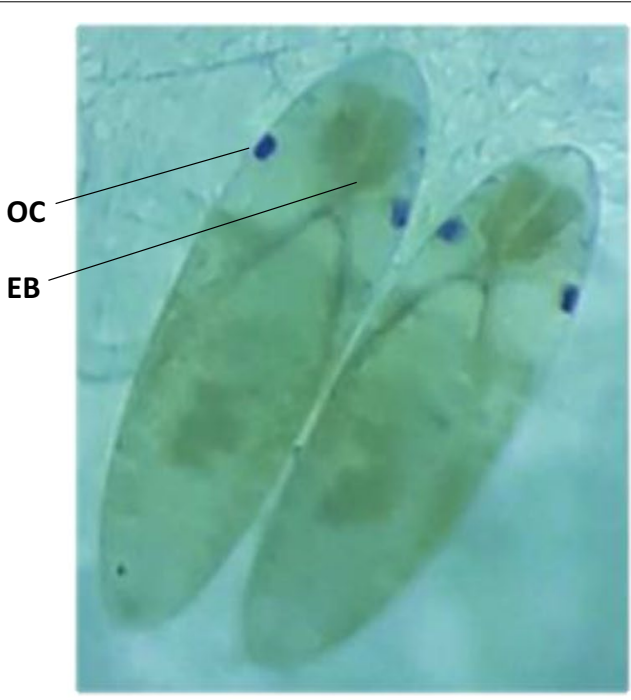

b

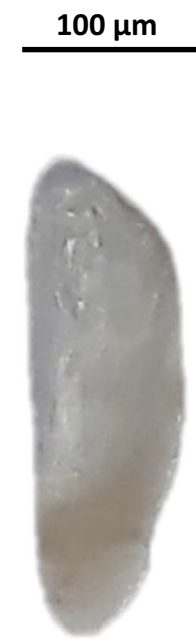

C

Fig. 6 Morphology of pharate larvae (dorsal view) (a, b) and unhatched incomplete embryo (c) of Aedes aegypti obtained from this study. Body regions of the pharate larvae are labeled, namely, the head $(\mathrm{H})$, thorax $(\mathrm{T})$, abdominal segments (AS), and respiratory siphon (RS), as well as the ocelli (Oc) and egg burster (EB)

Table 2 Descriptive statistics for PPL, HRs, and ROs of wet season-collected Ae. aegypti in the Philippine big islands by temperature

\begin{tabular}{|c|c|c|c|c|c|c|c|}
\hline \multirow[t]{2}{*}{ Big island } & \multirow[t]{2}{*}{ Temperature $\left({ }^{\circ} \mathrm{C}\right)$} & \multicolumn{2}{|c|}{ PPL (\%) } & \multicolumn{2}{|c|}{ HRs (\%) } & \multicolumn{2}{|l|}{ ROs } \\
\hline & & Mean & SD & Mean & SD & Mean & SD \\
\hline \multirow[t]{3}{*}{ Luzon } & 18 & 15.73 & 1.43 & 39.29 & 6.20 & 24.67 & 2.42 \\
\hline & 25 & 10.27 & 4.12 & 57.01 & 11.69 & 26.67 & 2.58 \\
\hline & 38 & 7.33 & 2.85 & 2.50 & 3.39 & 1.17 & 1.33 \\
\hline \multirow[t]{3}{*}{ Visayas } & 18 & 7.30 & 1.34 & 19.16 & 4.75 & 15.83 & 3.55 \\
\hline & 25 & 6.41 & 0.49 & 27.44 & 5.22 & 20.17 & 0.98 \\
\hline & 38 & 2.96 & 0.47 & 19.11 & 8.72 & 10.17 & 3.13 \\
\hline \multirow[t]{3}{*}{ Mindanao } & 18 & 6.35 & 1.50 & 33.34 & 11.34 & 22.67 & 2.94 \\
\hline & 25 & 6.79 & 1.48 & 30.31 & 10.71 & 23.50 & 3.94 \\
\hline & 38 & 3.53 & 0.56 & 1.19 & 1.22 & 2.00 & 2.45 \\
\hline \multirow{3}{*}{$\begin{array}{l}\text { Philippines (overall } \\
\text { mean) }\end{array}$} & 18 & 9.79 & 24.89 & 30.59 & 62.76 & 21.06 & 26.33 \\
\hline & 25 & 7.82 & 16.36 & 38.25 & 89.94 & 23.44 & 20.68 \\
\hline & 38 & 4.61 & 13.96 & 7.68 & 53.70 & 4.58 & 25.84 \\
\hline
\end{tabular}


unable to adjust to their environment (c). Pharate larvae inside the egg chorion completed embryogenesis but did not hatch when externally stimulated by ascorbate, suggesting they were in quiescence towards the end of embryogenesis [22, 32-34].

Across the big islands during the wet season, the overall mean PPL (4.61\%) (Table 2), HRs (7.68\%), and ROs (4.58) were lowest at $38{ }^{\circ} \mathrm{C}$. Overall mean HR (38.25\%) and RO (23.44) were highest at $25^{\circ} \mathrm{C}$, whereas mean PPL were highest at $18{ }^{\circ} \mathrm{C}(9.79 \%)$. Within the big islands, the highest mean PPL (Table 2) were recorded at $18^{\circ} \mathrm{C}$ for Luzon (15.73\%) and Visayas (7.3\%), and at $25{ }^{\circ} \mathrm{C}$ for Mindanao (6.79\%). For Luzon and Visayas, the highest mean HR (57.01\% and $27.44 \%$, respectively) and RO (26.67 and 20.17, respectively) were recorded at $25{ }^{\circ} \mathrm{C}$. Mindanao had the highest mean HR (33.34\%) (Table 2) at $18{ }^{\circ} \mathrm{C}$ and highest mean $\mathrm{RO}(23.50)$ at $25^{\circ} \mathrm{C}$. Mean PPL, $\mathrm{HR}$, and RO were lowest at $38^{\circ} \mathrm{C}$ for Luzon, Visayas, and Mindanao (Additional file 1: Dataset S1).

\section{Development-related phenotypes of dry season-collected} Ae. aegypti

Overall mean PPL and RO of dry season-collected Ae. aegypti were highest at $18{ }^{\circ} \mathrm{C}$ for both experimental $(14.19 \%$ and 2.89 , respectively) and control $(15.82 \%$ and 3.33 , respectively) photoperiods (Table 3 ). Overall mean HR was highest at $25^{\circ} \mathrm{C}$ for both experimental and control $(44.15 \%$ and $38.17 \%$, respectively) photoperiods. Lowest mean PPL, HR, and RO were recorded at $38{ }^{\circ} \mathrm{C}$ for both control $(7.57 \%, 2.12 \%$, and 0.33 , respectively) and experimental $(8.86 \%, 2.70 \%$, and 1.94 , respectively) photoperiods. Within each big island, mean HRs of mosquitoes were highest at $25^{\circ} \mathrm{C}$ and lowest at $38{ }^{\circ} \mathrm{C}$ for the experimental photoperiod (Table 3). Likewise, mean ROs were highest at both 18 and $38^{\circ} \mathrm{C}$ for mosquitoes in the Visayas, at $18{ }^{\circ} \mathrm{C}$ for those in Mindanao, and at $25^{\circ} \mathrm{C}$ for those in Luzon (Additional file 2: Dataset S2).

Table 3 Descriptive statistics for PPL, HRs, and ROs by photoperiod (control: 12L:12D; experimental: 13.5L:10.5D) and temperature of dry season Ae. aegypti

\begin{tabular}{|c|c|c|c|c|c|c|c|c|}
\hline \multirow[t]{2}{*}{ Big island } & \multirow[t]{2}{*}{ Photoperiod } & \multirow[t]{2}{*}{ Temperature $\left({ }^{\circ} \mathrm{C}\right)$} & \multicolumn{2}{|c|}{ PPL (\%) } & \multicolumn{2}{|c|}{ HRs (\%) } & \multicolumn{2}{|l|}{ ROs } \\
\hline & & & Mean & SD & Mean & SD & Mean & SD \\
\hline \multirow[t]{6}{*}{ Luzon } & \multirow[t]{3}{*}{ Control } & 18 & 16.72 & 12.50 & 34.40 & 22.65 & 3.17 & 1.51 \\
\hline & & 25 & 14.38 & 11.85 & 49.64 & 38.07 & 3.67 & 1.03 \\
\hline & & 38 & 5.85 & 12.65 & 4.17 & 20.41 & 0.17 & 0.82 \\
\hline & \multirow[t]{3}{*}{ Experimental } & 18 & 14.29 & 13.57 & 37.50 & 43.25 & 3.50 & 1.10 \\
\hline & & 25 & 8.44 & 10.19 & 53.25 & 40.44 & 3.83 & 0.82 \\
\hline & & 38 & 10.61 & 3.83 & 3.08 & 8.74 & 1.00 & 2.53 \\
\hline \multirow[t]{6}{*}{ Visayas } & \multirow[t]{3}{*}{ Control } & 18 & 16.35 & 11.81 & 31.01 & 62.80 & 3.33 & 1.63 \\
\hline & & 25 & 9.31 & 9.78 & 43.04 & 19.10 & 3.00 & 1.79 \\
\hline & & 38 & 8.61 & 7.49 & 2.19 & 8.52 & 0.83 & 2.34 \\
\hline & \multirow[t]{3}{*}{ Experimental } & 18 & 14.26 & 16.94 & 38.04 & 62.80 & 2.67 & 3.50 \\
\hline & & 25 & 11.59 & 3.76 & 44.68 & 19.10 & 2.50 & 3.52 \\
\hline & & 38 & 7.49 & 5.54 & 2.94 & 8.52 & 2.67 & 3.27 \\
\hline \multirow[t]{6}{*}{ Mindanao } & \multirow[t]{3}{*}{ Control } & 18 & 14.38 & 7.70 & 34.55 & 39.71 & 3.50 & 2.45 \\
\hline & & 25 & 11.89 & 11.47 & 21.82 & 33.78 & 2.67 & 1.03 \\
\hline & & 38 & 8.23 & 17.46 & 0.00 & 0.00 & 0.00 & 0.00 \\
\hline & \multirow[t]{3}{*}{ Experimental } & 18 & 14.02 & 8.39 & 16.87 & 24.00 & 2.50 & 3.03 \\
\hline & & 25 & 10.83 & 8.54 & 34.52 & 44.48 & 2.00 & 3.10 \\
\hline & & 38 & 8.49 & 6.68 & 2.07 & 3.85 & 2.17 & 2.34 \\
\hline \multirow{6}{*}{$\begin{array}{l}\text { Philippines } \\
\text { (average) }\end{array}$} & \multirow[t]{3}{*}{ Control } & 18 & 15.82 & 5.22 & 33.32 & 15.95 & 3.33 & 0.91 \\
\hline & & 25 & 11.86 & 5.62 & 38.17 & 22.19 & 3.11 & 0.76 \\
\hline & & 38 & 7.57 & 6.32 & 2.12 & 6.17 & 0.33 & 0.77 \\
\hline & \multirow[t]{3}{*}{ Experimental } & 18 & 14.19 & 6.31 & 30.80 & 23.93 & 2.89 & 1.37 \\
\hline & & 25 & 10.28 & 3.99 & 44.15 & 18.83 & 2.78 & 1.52 \\
\hline & & 38 & 8.86 & 2.90 & 2.70 & 3.50 & 1.94 & 1.47 \\
\hline
\end{tabular}


Table 4 MANOVA results using a generalized linear model for the main and interaction effects of big island, altitude, and temperature on PPL, HRs, and ROs between wet (2017) and dry (2018) season Ae. aegypti across all Philippine sites

\begin{tabular}{|c|c|c|c|c|c|}
\hline Sources of variation & Pillai's trace & $F$ & Hypothesis $d f$ & Error $d f$ & $P$-value \\
\hline \multicolumn{6}{|l|}{ Main effects } \\
\hline Season & 0.959 & 971.809 & 3.000 & 124.0 & $<0.001$ \\
\hline Big island & 0.380 & 9.781 & 6.000 & 250.0 & $<0.001$ \\
\hline Altitude & 0.010 & 0.430 & 3.000 & 124.0 & 0.732 \\
\hline Temperature & 0.993 & 41.103 & 6.000 & 250.0 & $<0.001$ \\
\hline \multicolumn{6}{|l|}{ Interaction effects } \\
\hline Season $\times$ big island & 0.179 & 4.086 & 6.000 & 250.0 & 0.001 \\
\hline Season $\times$ altitude & 0.004 & 0.161 & 3.000 & 124.0 & 0.922 \\
\hline Season $\times$ temperature & 0.888 & 33.276 & 6.000 & 250.0 & $<0.001$ \\
\hline Big island $\times$ altitude & 0.042 & 0.885 & 6.000 & 250.0 & 0.506 \\
\hline Big island $\times$ temperature & 0.685 & 9.314 & 12.000 & 378.0 & $<0.001$ \\
\hline Altitude $\times$ temperature & 0.009 & 0.187 & 6.000 & 250.0 & 0.980 \\
\hline Season $\times$ big island $\times$ altitude & 0.025 & 0.519 & 6.000 & 250.0 & 0.794 \\
\hline Season $\times$ big island $\times$ temperature & 0.517 & 6.552 & 12.000 & 378.0 & $<0.001$ \\
\hline Season $\times$ altitude $\times$ temperature & 0.044 & 0.928 & 6.000 & 250.0 & 0.475 \\
\hline Big island $\times$ altitude $\times$ temperature & 0.194 & 2.180 & 12.000 & 378.0 & 0.012 \\
\hline Season $\times$ big island $\times$ altitude $\times$ temperature & 0.161 & 1.783 & 12.000 & 378.0 & 0.049 \\
\hline
\end{tabular}

Bold $P$-values mean significant at $P=0.05$

\section{Full-factorial MANOVA results in both seasons of $A e$. aegypti}

The assumption of no multicollinearity among the dependent variables (PPL, HR, and RO) was satisfied in the given data set for MANOVA. The assumption of multicollinearity was not an issue among the independent variables of MANOVA because these categorical variables created independent groups upon which dependent variables were compared for significant differences. Results of the GLM for full-factorial MANOVA (Table 4) using Pillai's trace, the most robust among SPSS tests (v. 21; IBM Corporation, NY, USA), showed no significant $(P>0.05)$ main effects of altitude on PPL, HR, or
RO, but were significantly $(p<0.001)$ affected by the main effects of season, temperature, and big island. Moreover, significant interaction effects across all sites between (1) season and big island $(P<0.01)$, $(2)$ season and temperature $(P<0.001)$, and $(3)$ big island and temperature $(P<0.001)$, and among $(1)$ season, big island, and temperature $(P<0.001),(2)$ big island, altitude, and temperature $(P<0.05)$, and $(3)$ season, big island, altitude, and temperature $(P<0.05)$ were observed for all phenotypes. The mean temperatures were similar between the wet $\left(\min =23.87^{\circ} \mathrm{C} ; \max =32.37^{\circ} \mathrm{C}\right)$ and $\operatorname{dry}\left(\min =24.28^{\circ} \mathrm{C}\right.$; $\max =34.07^{\circ} \mathrm{C}$ ) seasons (Fig. 2) during the study period.

Table 5 MANOVA results using a generalized linear model for the main and interaction effects of big island, altitude, and temperature on PPL, HRs, and ROs of wet season Ae. aegypti across all Philippine sites

\begin{tabular}{|c|c|c|c|c|c|}
\hline Sources of variation & Pillai's trace & F & Hypothesis $d f$ & Error $d f$ & $P$-value \\
\hline \multicolumn{6}{|l|}{ Main effects } \\
\hline Big island & 0.926 & 10.060 & 6.000 & 70.000 & $<0.001$ \\
\hline Altitude & 0.005 & 0.061 & 3.000 & 34.000 & 0.980 \\
\hline Temperature & 1.197 & 17.407 & 6.000 & 70.000 & $<0.001$ \\
\hline \multicolumn{6}{|l|}{ Interaction effects } \\
\hline Big island $\times$ altitude & 0.084 & 0.513 & 6.000 & 70.000 & 0.797 \\
\hline Big island $\times$ temperature & 1.382 & 7.692 & 12.000 & 108.000 & $<0.001$ \\
\hline Altitude $\times$ temperature & 0.225 & 1.479 & 6.000 & 70.000 & 0.198 \\
\hline Big island $\times$ altitude $\times$ temperature & 0.397 & 1.371 & 12.000 & 108.000 & 0.191 \\
\hline
\end{tabular}

Bold $P$-values mean significant at $P=0.05$ 
Table 6 MANOVA results using a generalized linear model for the main and interaction effects of big island, altitude and temperature on PPL, HRs, and ROs of dry season Ae. aegypti across all Philippine sites

\begin{tabular}{|c|c|c|c|c|c|}
\hline Sources of variation & Pillai's trace & $F$ & Hypothesis $d f$ & Error $d f$ & $P$-value \\
\hline \multicolumn{6}{|l|}{ Main effects } \\
\hline Big island & 0.226 & 3.019 & 6.000 & 142.000 & 0.008 \\
\hline Altitude & 0.027 & 0.637 & 3.000 & 70.000 & 0.594 \\
\hline Temperature & 0.940 & 20.984 & 6.000 & 142.000 & $<0.001$ \\
\hline Photoperiod & 0.026 & 0.615 & 3.000 & 70.000 & 0.607 \\
\hline \multicolumn{6}{|l|}{ Interaction effects } \\
\hline Big island $\times$ altitude & 0.022 & 0.264 & 6.000 & 142.000 & 0.953 \\
\hline Big island $\times$ temperature & 0.251 & 1.647 & 12.000 & 216.000 & 0.081 \\
\hline Big island $\times$ photoperiod & 0.015 & 0.185 & 6.000 & 142.000 & 0.981 \\
\hline Altitude $\times$ temperature & 0.043 & 0.519 & 6.000 & 142.000 & 0.793 \\
\hline Altitude $\times$ photoperiod & 0.023 & 0.540 & 3.000 & 70.000 & 0.656 \\
\hline Temperature $\times$ photoperiod & 0.260 & 3.529 & 6.000 & 142.000 & 0.003 \\
\hline Big island $\times$ altitude $\times$ temperature & 0.078 & 0.483 & 12.000 & 216.000 & 0.923 \\
\hline Big island $\times$ altitude $\times$ photoperiod & 0.111 & 1.387 & 6.000 & 142.000 & 0.224 \\
\hline Big island $\times$ temperature $\times$ photoperiod & 0.256 & 1.679 & 12.000 & 216.000 & 0.073 \\
\hline Altitude $\times$ temperature $\times$ photoperiod & 0.065 & 0.799 & 6.000 & 142.000 & 0.572 \\
\hline Big island $\times$ altitude $\times$ temperature $\times$ photoperiod & 0.116 & 0.724 & 12.000 & 216.000 & 0.727 \\
\hline
\end{tabular}

Bold $P$-values mean significant at $P=0.05$

\section{Overall full-factorial MANOVA results within season Wet season-collected Ae. aegypti}

GLM results of MANOVA within the wet season (Table 5) showed significant $(P<0.01)$ main effects of big island and temperature on PPL, HRs, and ROs of Ae. aegypti. The significant $(P<0.01)$ interaction effects were only observed between big island and temperature on all phenotypes.

\section{Dry season-collected Ae. aegypti}

Interestingly, the GLM of MANOVA results for dry season-collected Ae. aegypti (Table 6) were similar to those in the wet season. The main effects of big island $(P<0.05)$ and temperature $(P<0.01)$ on PPL, HRs, and ROs were significant. The significant $(P<0.01)$ interaction effects for dry season mosquitoes were detected

Table 7 Results of MANOVA on the main and interaction effects of the Philippine big island, altitude, and temperature on PPL, HRs, and ROs of wet season Ae. aegypti

\begin{tabular}{|c|c|c|c|c|c|c|c|}
\hline \multirow[t]{2}{*}{ Source } & \multirow[t]{2}{*}{$d f$} & \multicolumn{2}{|l|}{ PPL (\%) } & \multicolumn{2}{|l|}{ HRs (\%) } & \multicolumn{2}{|l|}{ ROs } \\
\hline & & $F$ & $P$-value & $F$ & $P$-value & $F$ & $P$-value \\
\hline Model & 17 & 9.978 & 0.000 & 15.761 & 0.000 & 45.244 & $<0.001$ \\
\hline Intercept & 1 & 708.559 & 0.000 & 604.826 & 0.000 & 2373.581 & $<0.001$ \\
\hline Big island & 2 & 44.292 & 0.000 & 12.928 & 0.000 & 3.462 & 0.042 \\
\hline Altitude & 1 & 0.050 & 0.825 & 0.161 & 0.690 & 0.150 & 0.701 \\
\hline Temperature & 2 & 29.460 & 0.000 & 79.019 & 0.000 & 318.370 & $<0.001$ \\
\hline Big island $\times$ altitude & 2 & 0.041 & 0.960 & 0.562 & 0.575 & 1.260 & 0.296 \\
\hline Big island $\times$ temperature & 4 & 4.306 & 0.006 & 17.996 & 0.000 & 26.384 & $<0.001$ \\
\hline Altitude $\times$ temperature & 2 & 0.600 & 0.554 & 1.567 & 0.223 & 0.407 & 0.669 \\
\hline Big island $\times$ altitude $\times$ temperature & 4 & 0.891 & 0.479 & 1.911 & 0.130 & 4.118 & 0.008 \\
\hline Error & 36 & & & & & & \\
\hline Total & 54 & & & & & & \\
\hline
\end{tabular}

Bold $P$-values mean significant at $P=0.05$ 
Table 8 Results of MANOVA on the main and interaction effects of altitude, temperature and photoperiod on PPL, HRs, and ROs of dry season Ae. aegypti across the Philippine big islands

\begin{tabular}{|c|c|c|c|c|c|c|c|}
\hline \multirow[t]{2}{*}{ Source } & \multirow[t]{2}{*}{$d f$} & \multicolumn{2}{|l|}{ PPL (\%) } & \multicolumn{2}{|l|}{ HR (\%) } & \multicolumn{2}{|l|}{$\mathrm{RO}$} \\
\hline & & $F$ & $P$-value & $F$ & $P$-value & $F$ & $P$-value \\
\hline Model & 35 & 1.027 & 0.450 & 4.092 & 0.000 & 3.131 & $<0.001$ \\
\hline Big island & 2 & 0.065 & 0.937 & 5.041 & 0.009 & 1.318 & 0.274 \\
\hline Altitude & 1 & 0.113 & 0.737 & 1.302 & 0.258 & 1.119 & 0.294 \\
\hline Photoperiod & 1 & 0.321 & 0.573 & 0.178 & 0.674 & 1.490 & 0.226 \\
\hline Temperature & 2 & 12.314 & 0.000 & 53.678 & 0.000 & 30.801 & $<0.001$ \\
\hline Big island $\times$ altitude & 2 & 0.170 & 0.844 & 0.475 & 0.624 & 0.086 & 0.918 \\
\hline Big island $\times$ photoperiod & 2 & 0.065 & 0.937 & 0.145 & 0.865 & 0.139 & 0.870 \\
\hline Big island $\times$ temperature & 4 & 0.111 & 0.978 & 1.255 & 0.296 & 3.245 & 0.017 \\
\hline Altitude $\times$ photoperiod & 1 & 0.113 & 0.738 & 1.311 & 0.256 & 0.325 & 0.571 \\
\hline Altitude $\times$ temperature & 2 & 0.369 & 0.693 & 0.947 & 0.393 & 0.881 & 0.419 \\
\hline Photoperiod $\times$ temperature & 2 & 0.741 & 0.480 & 0.605 & 0.549 & 8.603 & $<0.001$ \\
\hline Big island $\times$ altitude $\times$ photoperiod & 2 & 0.170 & 0.844 & 1.879 & 0.160 & 0.523 & 0.595 \\
\hline Big island $\times$ altitude $\times$ temperature & 4 & 0.238 & 0.916 & 0.714 & 0.585 & 0.265 & 0.900 \\
\hline Big island $\times$ photoperiod $\times$ temperature & 4 & 1.194 & 0.321 & 1.091 & 0.367 & 1.172 & 0.330 \\
\hline Altitude $\times$ photoperiod $\times$ temperature & 2 & 0.280 & 0.757 & 0.300 & 0.742 & 1.040 & 0.359 \\
\hline Big island $\times$ altitude $\times$ photoperiod $\times$ temperature & 4 & 0.221 & 0.926 & 0.508 & 0.730 & 0.285 & 0.887 \\
\hline Error & 72 & & & & & & \\
\hline Total & 108 & & & & & & \\
\hline
\end{tabular}

Bold $P$-values mean significant at $P=0.05$

only between temperature and photoperiod for both control and experimental photoperiods.

\section{Pharate larvae \\ Wet season}

MANOVA results (Table 7) showed that the overall PPL of wet season Ae. aegypti across sites differed significantly $(P<0.01)$ by big island and temperature and not by altitude $(P>0.05)$. Results of Tukey's post hoc test showed that the overall PPL across sites were significantly $(P<0.01)$ lowest at $38{ }^{\circ} \mathrm{C}$ and significantly highest at $18{ }^{\circ} \mathrm{C}(P<0.05)$. A few surviving pharate larvae at $38^{\circ} \mathrm{C}$ suggest their adaptive ability. Unhatched incompletely embryonated and severely desiccated eggs (Fig. 6c) were prevalent among those exposed at $38^{\circ} \mathrm{C}$.

\section{Dry season}

MANOVA results (Table 8 ) showed that only temperature had a significant $(P=0.00)$ main effect on PPL across all sites of dry season samples. Tukey's post hoc analyses showed that PPL were significantly $(P<0.01)$ highest at $18{ }^{\circ} \mathrm{C}$, and were not significantly different $(P>0.05)$ at 25 and $38{ }^{\circ} \mathrm{C}$. Interaction effects between and among independent variables on PPL were not significant $(P>0.05)$.

\section{Hatch rates (HRs)}

\section{Wet season}

Results of MANOVA (Table 7) revealed that the overall HRs of wet season Ae. aegypti F1 eggs across all sites differed significantly $(P=0.00)$ by main effects of both temperature and big island. The results of Tukey's post hoc test showed that HRs were significantly $(P<0.001)$ lowest at $38^{\circ} \mathrm{C}$ and significantly $(P<0.05)$ highest at $25^{\circ} \mathrm{C}$. There was also a significant $(P<0.001)$ interaction between big island and temperature that affected the HRs of F1 eggs across all sites. These findings constitute the first such report in the tropics, as most studies have been done in temperate and subtropical regions [35-38].

\section{Dry season}

Results of MANOVA (Table 8) showed that big island $(P=0.02)$ and temperature $(P=0.00)$ had significant main effects on HRs of dry season Ae. aegypti across all sites. The results of Tukey's post hoc test showed that HRs were significantly $(P<0.05)$ highest at $25^{\circ} \mathrm{C}$, and were significantly $(P<0.001)$ lowest at $38{ }^{\circ} \mathrm{C}$. No significant $(P>0.05)$ interaction effects were detected between and among big islands, altitude, temperature, and photoperiod on HRs of dry season-collected Ae. aegypti. 


\section{Reproductive outputs (ROs) Wet season}

MANOVA results (Table 7) revealed that the overall ROs of wet season Ae. aegypti F1 egg cohorts across all sites differed significantly by main effects of big island $(P<0.05)$ and temperature $(P<0.01)$. The results of Tukey's post hoc test showed that RO was significantly $(P<0.001)$ lowest at $38{ }^{\circ} \mathrm{C}$ and significantly $(P<0.05)$ highest at $25^{\circ} \mathrm{C}$. Significant interaction effects between big island and temperature $(P<0.01)$ and among big island, altitude, and temperature $(P<0.01)$ were observed on the ROs of wet season-collected $A e$. aegypti egg cohorts across all sites.

\section{Dry season}

The results of MANOVA (Table 8) showed a significant main effect for temperature $(P<0.01)$ on ROs of dry season Ae. aegypti across the big islands. The results of Tukey's post hoc test showed that ROs were significantly $(P<0.001)$ lowest at $38{ }^{\circ} \mathrm{C}$, and did not significantly $(P>0.05)$ differ between 18 and $25^{\circ} \mathrm{C}$. Interaction effects between big island and temperature $(P<0.05)$ and between photoperiod and temperature $(P<0.01)$ significantly influenced the ROs of dry season Ae. aegypti across all big islands.

\section{Discussion}

Results of full-factorial MANOVA in both seasons suggest that significant differences in Ae. aegypti phenotypes are not associated with season alone but rather their interaction with temperature and perhaps the associated factors of the Philippine big islands such as their ecology, available breeding sites, and day lengths due to latitudinal locations. The big islands represent different latitudes, with Mindanao being the closest to the equator $\left(8^{\circ} \mathrm{N}\right)$, followed by Visayas $\left(10^{\circ} \mathrm{N}\right)$, and then Luzon $\left(14-16^{\circ} \mathrm{N}\right.$; Table 1). Latitudinal differences bring about variation in the amount of sunlight received at a location due to the angle of the sun's rays [39]; thus, the photoperiod regulates the life history stages [40]. At $10^{\circ}$ latitude, photoperiodism in insects has been observed [41]. Moreover, an increase in latitude results in a decrease in temperature [42], indicating that the sites farther from the equator with higher altitude have relatively lower temperature (Fig. 2) than those near the equator. Temperature greatly influences the mosquito population and disease transmission, as it directly affects the abundance of breeding sites, rate of mosquito development, reproduction, and survival $[43,44]$. These interaction effects on Ae. aegypti suggest that their dynamics and apparent disease transmission require a careful evaluation of the existing vector and dengue control programs. Previously, Edillo et al. [45] reported a gradual increase in the minimum rate of dengue virus-infected Ae. aegypti in Cebu city, Philippines, from zero in wet months to 48.22 infected mosquitoes for every 1000 in mid-dry season (April), consistent with Angel and Joshi [46] and Thongrungkiat et al. [47]. Although control interventions were recommended in the non-outbreak dry season in order to suppress the re-emergence of dengue transmission in the next outbreak wet season, the common practice of the enhanced $4 \mathrm{~S}$ strategy was conducted only during the epidemic wet season. The results of the current study suggest that the enhanced $4 \mathrm{~S}$ strategy should be implemented year-round owing to the absence of seasonal differences in the PPL, $\mathrm{HR}$, and $\mathrm{RO}$ of Ae. aegypti across the big islands as a consequence of global warming. Newly emerged pharate first-instar larvae of Ae. aegypti that had undergone prolonged quiescence were shown to be vulnerable to environmental stress [48]. Thus, targeting them year-round would greatly reduce the mosquito vector populations, with particular emphasis on Visayas at $10^{\circ} \mathrm{N}$ latitude [41] and Mindanao at $8^{\circ} \mathrm{N}$ latitude.

Climate change-induced increased temperature and rainfall variability are likely to have the greatest impacts on human health in the Philippines $[49,50]$. This scenario might be exacerbated in rural highlands that do not have direct water pipelines, forcing households to store water in plastic drums for domestic use. This lack of a proper water service system facilitates year-round breeding of mosquitoes in their expanded distribution to rural highlands, as also confirmed in our separate study on the population genetics of Philippine Ae. aegypti based on gene flow, posing a challenge for vector control programs.

Pharate larvae of Ae. aegypti were highest at $18{ }^{\circ} \mathrm{C}$ in both seasons in the current study, which is consistent with the results reported by Farnesi et al. [31]. Moreover, Clements [34], Diniz et al. [14], and Vinogradova [13] noted that as pharate larvae of Ae. aegypti are subjected to unfavorable environmental conditions (i.e., temperature change), temporary developmental arrest and impeded larval hatching follow, which is consistent with the current results. Diapausing pharate larvae of Ae. albopictus may be more metabolically active at $21{ }^{\circ} \mathrm{C}$ than at lower temperatures and spend considerable time at higher temperatures during fall before the onset of winter [11]. The current results corroborate those of related studies [51-53] showing that desiccation resistance of these eggs is an important ecological trait that might be associated with their adaptation to drought tolerance, invasion success towards higher altitudes, and competitive outcomes. Moreover, quiescence depends on differences in eggshell composition and structural and physiological changes, which result in reduced metabolism among pharate larvae contained within the egg chorion [14]. The eggs, not the embryos, are able to 
resist desiccation, because quiescence can only be initiated after completed embryogenesis, hence the term "egg resistance to desiccation." The chitin synthase gene promotes chitin synthesis, secreted into the egg's extracellular space, which leads to the formation of the serosal cuticle for egg desiccation resistance [14, 54]. The high amount of fatty acyl-CoA elongase in mature oocytes of insects produces hydrocarbons to regulate water loss; its abundance varies in temperate Ae. albopictus exposed to long and short days but is maintained at a relatively constant amount in tropical populations [55]. Poelchau et al. [11] found that the gene expression of diapausing Ae. albopictus eggs converged over time towards quiescence. Metabolic differences, particularly in lipid storage, serve as the primary distinguishing factor between gene expression of early diapause and quiescence. Exogenous control of quiescence denotes its non-reliance on rapid gene activation and macromolecule synthesis or degradation [14]. Quiescence begins when the embryo (pharate larva) receives an external unfavorable stimulus (i.e., rapid change in humidity and/or temperature), whereas gravid females initiate the expression of certain genes to be transferred to the offspring, and the embryo enters diapause. Egg quiescence is temporary and reversible, and has been shown in other mosquito species such as Ae. flavopictus, Ae. galloisi, Ae. riversi, Anopheles aquasalis, An. gambiae, and Culex quinquefasciatus [14].

Overall, the mean HRs of Ae. aegypti were highest at $25{ }^{\circ} \mathrm{C}$ and lowest at $38{ }^{\circ} \mathrm{C}$ in both the wet season (20172018) and dry season (2018), and were significantly influenced by temperature and big island with associated day lengths due to latitudinal differences (Table 1). During the wet season, mean HRs were highest at $25^{\circ} \mathrm{C}$ for mosquitoes in Luzon and Visayas and at $18{ }^{\circ} \mathrm{C}$ for those in Mindanao. During the dry season, mean HRs were highest at $25{ }^{\circ} \mathrm{C}$ for all mosquitoes in all big islands. Aedes aegypti eggs from highlands that were exposed at $38{ }^{\circ} \mathrm{C}$ and hatched into larvae imply their apparent gradual adaptation as they expand their distribution to higher altitude, i.e., up to $1489 \mathrm{~m}$ ASL in BG sub-sites. The range of temperature tolerance for Ae. aegypti is between $10^{\circ} \mathrm{C}$ [32, 56-58] and $32{ }^{\circ} \mathrm{C}[58]$, but up to $35^{\circ} \mathrm{C}$ for short periods of flight [57] and maximum tolerance for embryonic development [31]. Egg viability between 16 and $31^{\circ} \mathrm{C}$ was above $80 \%$, comparable to Ae. aegypti presence in the tropics and subtropics [31]. Likewise, Dhimal et al. [10] found Ae. aegypti and Ae. albopictus up to $1350 \mathrm{~m}$ ASL in Katmandu Valley, Nepal, and a few between $1750 \mathrm{~m}$ and $2100 \mathrm{~m} \mathrm{ASL}$ in the mountains. Moreover, results were consistent with the findings of De Majo et al. [38], who reported that the proportion of hatched eggs of Ae. aegypti in Argentina was positively associated with immersion and pre-immersion temperature and photoperiod. Lacour et al. [22] exposed both tropical and temperate Ae. albopictus to short-day and long-day photoperiods, and found that only the eggs of temperate strains maternally reared under short days entered diapause, with an HR of $0.1-13.6 \%$.

$\mathrm{RO}$ results indicate the plasticity of Ae. aegypti as they adapt to their local weather conditions across the Philippine big islands during the hotter, dry and longer day lengths in summer $[59,60]$. During the dry season with experimental (longer) photoperiod (Table 3), ROs of mosquitoes in Visayas $\left(10^{\circ} \mathrm{N}\right.$ latitude) ranged from 2.5 to 2.67 , and those in Mindanao $\left(8^{\circ} \mathrm{N}\right.$ latitude) from 2 to 2.5 , in all three temperatures, but for those in Luzon, mean RO (3.83) was highest at $25^{\circ} \mathrm{C}$ and lowest at $38^{\circ} \mathrm{C}$ (1.0). RO results in Visayas and Mindanao were consistent with the findings of Denlinger [41], who reported that several insect species show photoperiodism because seasonal changes in day length are greater within $10^{\circ} \mathrm{N}$ of the equator. Moreover, a larger diurnal temperature range in the highlands during the dry season might also have contributed to the reduction in $\mathrm{RO}$, consistent with results reported by Carrington et al. [60]. Overall, mean ROs across the big islands were lowest at $38{ }^{\circ} \mathrm{C}$ in both seasons, consistent with findings of Bar-Zeev [61]. Hence, temperature can dictate optimal conditions for arbovirus emergence and spread, and is considered a strong driver of transmission of vector-borne diseases.

In summary, we hypothesized that temperature, season, photoperiod as influenced by latitudinal differences, and altitude might play a role in the development-related phenotypes of Ae. aegypti F1 eggs. Three prevailing results for Ae. aegypti in both wet (2017-2018) and dry (2018) seasons across all sites were observed: (1) significant main effects of temperature, season, and big island on all phenotypes (PPL, HRs, and ROs), and (2) significant interaction effects on all the phenotypes of Ae. aegypti between the following: (i) season and big island, (ii) season and temperature, (iii) season, big island, and temperature, (iv) big island, altitude, and temperature, and (v) season, big island, altitude, and temperature. (3) Hence, season alone did not influence the phenotypic differences in Ae. aegypti because the average temperatures were similar between the two seasons of the study period (Fig. 2). Temperature not only affects quiescence directly by triggering it as an acyclic environmental change, but it also indirectly affects the initiation of dormancy by inhibiting complete embryogenesis [31]. The larval development time is significantly prolonged and lipid reserves are decreased, incurring fitness costs for larval viability and compromising adult mosquitoes' reproductive performance [13, 34]. Quiescence directly affects the 
survival of mosquito populations under adverse environmental conditions $[13,62]$. The environmental context of climate change and global warming is likely to contribute to the spread of Ae. aegypti and its pathogens in new areas [63].

Gould and Higgs [64] reported that climate is a major factor in arboviral evolution and transmission efficiency from arthropod vectors to vertebrate hosts such as humans. Viruses vary seasonally. In the case of dengue, virus isolation and detection in Ae. aegypti is higher during the dry season than in the wet season [45]. Transmission of dengue among humans is higher during the wet season, most especially during the early months of the wet season. Latitude and altitude associated with highlands and lowlands may influence the effects of critical photoperiod (CPP) among Ae. aegypti populations. This current study provides the link to related studies of $A e$. sierrensis and Ae. triseriatus that show these combined effects [65, 66]. Denlinger and Armbruster [12] suggested that the rapid evolution of the CPP in Ae. albopictus across the spatial climatic gradient of eastern North America may imply that mosquitoes quickly adjust their phenology (i.e., the cyclic and seasonal natural phenomena in relation to climate) to expand their geographic range and make the most of extended seasons associated with global warming.

\section{Conclusions}

In conclusion, development-related phenotypes (PPL, HRs, and ROs) of Ae. aegypti across Philippine study sites were significantly affected by temperature, season, and their latitudinal locations (i.e., big islands from $8^{\circ} \mathrm{N}$ to $16^{\circ} \mathrm{N}$ ) in wet and dry seasons of 2017-2018. Season alone did not influence the phenotypes between seasons, but rather its interaction effects with big island and/or temperature, and/or altitude. Pharate larval formation of $A e$. aegypti via egg quiescence in cold and hot conditions and their resistance to desiccation are important phenotypic adaptations. The capacity of mosquito eggs to survive for long periods has implications for the control of mosquitos and their potential to transmit human diseases. Thus, we recommend that a dengue prevention and control program in the Philippines, particularly the enhanced $4 \mathrm{~S}$ strategy, be implemented year-round rather than during the dengue epidemic wet season, with a particular focus in the Visayas and Mindanao. Reduction of breeding sites, covering of water storage containers, and hygiene and sanitation around households should be constant components of a community-based, integrated approach, combined with educational programs to increase knowledge and understanding of best practice [67]. Also, we recommend the installation of pipelines for the water supply system for householders in rural highlands to decrease potential breeding sites. Thus, the findings of this study can guide dengue and vector control programs to better respond to the effects of global warming, not just in the Philippines, but in the tropics in general.

\begin{abstract}
Abbreviations
PPL: Percent pharate larvae; HR: Hatching rate; RO: Reproductive output; RH: Relative humidity; $\mathrm{NaOCl}$ : Sodium hypochlorite; EDTA: Ethylenediaminetetraacetic acid; DW: Distilled water; CRD: Completely randomized design; GLM: Generalized linear model; MANOVA: Multivariate analyses of variance; DOH: Department of Health; PAGASA: Philippine Atmospheric, Geophysical and Astronomical Services Administration; CPP: Critical photoperiod.
\end{abstract}

\section{Supplementary Information}

The online version contains supplementary material available at https://doi. org/10.1186/s13071-022-05186-x.

Additional file 1: Dataset S1. Development-related phenotypes (PPL, $H R$ and $R O$ ) of Aedes aegypti for wet season (2017-2018).

Additional file 2: Dataset S2. Development-related phenotypes (PPL, HR and $\mathrm{RO}$ ) of Aedes aegypti for dry season (2018).

\section{Acknowledgements}

We thank our coordinators for Aedes collections (Alan Dargantes, Central Mindanao University, Bukidnon; Amelardo Taveros, Cagayan de Oro city; Chiara Dela Peña, Liloan, Cebu; Mayer Calma and Benny Sunga, Baguio city; and Liza Marie Erabon, Maintenance of the University of the Philippines [UPD]-Diliman, Quezon city). We also thank Enriqueta Reston, USC as SSPS consultant.

\section{Authors' contributions}

FE and AS conceptualized the research. FE and RRY supervised the research. $F E$, JEL, and RRY established coordinators for egg collections in Luzon, Visayas, and Mindanao. FE, RRY, AAB, RJH, BLF, GC, and JC performed the research. FE, RRY, BLF, GC and JC analyzed data. FE and RRY wrote the original manuscript. FE, RRY, AS, and JEL reviewed and edited the manuscript. All authors read and approved the final manuscript.

\section{Funding}

This study is supported by the funds from the Philippine Council of Health Research and Development_Department of Science and Technology, Manila and from the University of San Carlos, Cebu city, Philippines to FE.

\section{Availability of data and materials}

The meteorological data that support the findings of this study are available from the Philippine Atmospheric, Geophysical and Astronomical Services Administration (PAGASA) and were requested through the online portal of the Philippine Freedom of Information (foi.gov.ph) but restrictions apply to the availability of these data, which were used under specific terms and conditions for the current study, and so are not publicly available. Data are, however, available from the authors upon reasonable request and with permission of PAGASA. Datasets for development-related phenotypes (percent pharate larvae, hatching rate and reproductive output) of Ae. aegypti for wet (2017-2018) and dry (2018) seasons analyzed in this study are included in this published article and its supplementary information files.

\section{Declarations}

Ethics approval and consent to participate Not applicable.

Consent for publication

Not applicable. 


\section{Competing interests}

The authors declare that they have no competing interests.

\section{Author details}

${ }^{1}$ Mosquito Research Laboratory, Biology Department, University of San CarlosTalamban Campus, Cebu City, Philippines. ${ }^{2}$ National Institute of Molecular Biology and Biotechnology, University of the Philippines Diliman, Quezon City, Philippines. ${ }^{3}$ Functional Genetics of Infectious Diseases Unit, Institut Pasteur, Paris, France. ${ }^{4}$ Centre National de la Recherche Scientifique, 75015 Paris, France.

Received: 16 August 2021 Accepted: 1 February 2022

Published online: 05 March 2022

\section{References}

1. Khan J, Khan I, Amin I. A comprehensive entomological, serological and molecular study of 2013 dengue outbreak of Swat, Khyber Pakhtunkhwa, Pakistan. PLoS ONE. 2016:11:e0147416.

2. Capinha C, Rocha J, Sousa CA. Macroclimate determines the global range limit of Aedes aegypti. EcoHealth. 2014;11:420-8.

3. World Health Organization - Western Pacific Regional Office. Dengue Situation Update \# 625: Update on the dengue situation in the Western Pacific Region. 2021. https://www.who.int/docs/default-source/wpro--documents/emergency/surveillance/dengue/dengue-20210520.pdf? Status=Master\&sfvrsn=fc80101d_62. Accessed 2 Jul 2021.

4. Edillo FE, Halasa YA, Largo FM, Erasmo JN, Amoin NB, Alera MT, et al. Economic cost and burden of dengue in the Philippines. Am J Trop Med Hyg. 2015;92:360

5. Kutsuna S, Kato Y, Moi ML, Kotaki A, Ota M, Shinohara K, et al. Autochthonous dengue fever, Tokyo, Japan, 2014. Emerg Infect Dis. 2015;21:517.

6. Lourenço J, Recker M. The 2012 Madeira dengue outbreak: epidemiological determinants and future epidemic potential. PLoS Negl Trop Dis. 2014:8:e3083.

7. Department of Health. Reported dengue cases by month (January to July 2017-2020). Epidemiology Bureau. Public Health Surveillance Division. Requested August 31, 2020. Accessed 15 Sep 2020.

8. Chadee DD, Martinez R. Aedes aegypti (L.) in Latin American and Caribbean region: with growing evidence for vector adaptation to climate change? Acta Trop. 2016;156:137-43.

9. Williams CR, Mincham G, Ritchie SA, Viennet E, Harley D. Bionomic response of Aedes aegypti to two future climate change scenarios in far north Queensland, Australia: implications for dengue outbreaks. Parasites Vectors. 2014;7:1-7.

10. Dhimal M, Gautam I, Joshi HD, O'Hara RB, Ahrens B, Kuch U. Risk factors for the presence of chikungunya and dengue vectors (Aedes aegypti and Aedes albopictus), their altitudinal distribution and climatic determinants of their abundance in central Nepal. PLoS Negl Trop Dis. 2015;9:e0003545.

11. Poelchau MF, Reynolds JA, Elsik CG, Denlinger DL, Armbruster PA. RNASeq reveals early distinctions and late convergence of gene expression between diapause and quiescence in the Asian tiger mosquito Aedes albopictus. J Exp Biol. 2013;216:4082-90.

12. Denlinger DL, Armbruster PA. Mosquito diapause. Annu Rev Entomol. 2014;59:73-93.

13. Vinogradova EB. Diapause in aquatic insects, with emphasis on mosquitoes. In: Alekseev VR, de Stasio BT, Gilbert JJ, editors. Diapause in aquatic invertebrates: theory and human use. Springer, Netherlands: Dordrecht; 2007. p. 83-113.

14. Diniz DF, de Albuquerque CM, Oliva LO, de Melo-Santos MA, Ayres CF. Diapause and quiescence: dormancy mechanisms that contribute to the geographical expansion of mosquitoes and their evolutionary success. Parasites Vectors. 2017;10:1-3.

15. Christophers R. Aedes aegypti, the yellow fever mosquito. 1st ed. London: Cambridge University Press; 1960.

16. Soares-Pinheiro VC, Dasso-Pinheirob W, Trindade-Bezerrac JM, Tadeib WP. Eggs viability of Aedes aegypti Linnaeus (Diptera, Culicidae) under different environmental and storage conditions in Manaus, Amazonas. Brazil Braz J Biol. 2016. https://doi.org/10.1590/1519-6984.19815.
17. DOH. Dengue prevention and control program. 2020. https://doh.gov. ph/national-dengue-prevention-and-control-program. Accessed 28 Feb 2020.

18. Corporal-Lodangco IL, Leslie LM. Defining Philippine climate zones using surface and high-resolution satellite data. Procedia Comput Sci. 2017;114:324-32

19. AccuWeather-Philippines. 2017. https://www.accuweather.com Accessed 2 Aug 2018.

20. AccuWeather-Philippines. 2018. https://www.accuweather.com. Accessed 2 Aug 2018

21. Edillo FE, Roble ND, Otero ND II. The key breeding sites by pupal survey for dengue mosquito vectors, Aedes aegypti (Linnaeus) and Aedes albop ictus (Skuse), in Guba, Cebu City, Philippines. SE Asian J Trop Med Public Health. 2012:43:1365.

22. Lacour G, Vernichon F, Cadilhac N, Boyer S, Lagneau C, Hance T. When mothers anticipate: effects of the prediapause stage on embryo development time and of maternal photoperiod on eggs of a temperate and a tropical strains of Aedes albopictus (Diptera: Culicidae). J Insect Physiol. 2014;71:87-96

23. Costa-da-Silva AL, Navarrete FR, Salvador FS, Karina-Costa M, loshino RS, Azevedo DS, et al. Glytube: a conical tube and parafilm M-based method as a simplified device to artificially blood-feed the dengue vector mosquito, Aedes aegypti. PLoS ONE. 2013;8:e53816.

24. Degner EC, Harrington LC. A mosquito sperm's journey from male ejaculate to egg: Mechanisms, molecules, and methods for exploration. Mol Reprod Dev. 2016;83:897-911.

25. Zheng ML, Zhang DJ, Damiens DD, Lees RS, Gilles JR. Standard operating procedures for standardized mass rearing of the dengue and chikungunya vectors Aedes aegypti and Aedes albopictus (Diptera: Culicidae)-II-Egg storage and hatching. Parasites Vectors. 2015;8:1-7.

26. Brown HE, Smith C, Lashway S. Influence of the length of storage on Aedes aegypti (Diptera: Culicidae) egg viability. J Med Entomol. 2017:54:489-91.

27. Foster WA, Walker ED. Mosquitoes (Culicidae). In Medical and Veterinary Entomology. San Diego: Academic Press; 2002: 597. https://doi.org/10. 1016/B978-012510451-7/50014-1

28. Dickerson CZ. The effects of temperature and humidity on the eggs of Aedes aegypti (L.) and Aedes albopictus (Skuse) in Texas. Texas: A\&M University; 2007.

29. Faul F, Erdfelder E, Lang AG, Buchner A. G* Power 3: A flexible statistical power analysis program for the social, behavioral, and biomedical sciences. Behav Res Methods. 2007:39:175-91.

30. Vargas HC, Farnesi LC, Martins AJ, Valle D, Rezende GL. Serosal cuticle formation and distinct degrees of desiccation resistance in embryos of the mosquito vectors Aedes aegypti, Anopheles aquasalis and Culex quinquefasciatus. J Insect Physiol. 2014;62:54-60.

31. Farnesi LC, Martins AJ, Valle D, Rezende GL. Embryonic development of Aedes aegypti (Diptera: Culicidae): influence of different constant temperatures. Mem Inst Oswaldo Cruz. 2009;104:124-6.

32. Christophers SR. Aedes aegypti (L.), the yellow fever mosquito: its life history, bionomics and structure. Cambridge University Press; 1960.

33. Kliewer JW. Weight and hatchability of Aedes aegypti eggs (Diptera: Culicidae). Ann Entomol Soc Am. 1961;54:912-7.

34. Clements AN. The biology of mosquitoes. Volume 1: development, nutrition and reproduction. London: Chapman \& Hall; 1992.

35. Jia P, Chen X, Chen J, Lu L, Liu Q, Tan X. How does the dengue vector mosquito Aedes albopictus respond to global warming? Parasites Vectors. 2017:10:1-2.

36. Jia P, Lu L, Chen X, Chen J, Guo L, Yu X, et al. A climate-driven mechanistic population model of Aedes albopictus with diapause. Parasites Vectors. 2016;9:1-5

37. Giménez JO, Fischer S, Zalazar L, Stein M. Cold season mortality under natural conditions and subsequent hatching response of Aedes (Stegomyia) aegypti (Diptera: Culicidae) eggs in a subtropical city of Argentina. J Med Entomol. 2015;52:879-85.

38. De Majo MS, Montini P, Fischer S. Egg hatching and survival of immature stages of Aedes aegypti (Diptera: Culicidae) under natural temperature conditions during the cold season in Buenos Aires. Argentina J Med Entomol. 2015;54:106-13. 
39. Climate Science Investigation. Latitude and seasonal temperatures: how latitude affects temperature. 2019. http://www.ces.fau.edu/nasa/module3/why-does-temperature-vary/latitude.php. Accessed 28 Feb 2020.

40. Sockman KW, Hurlbert AH. How the effects of latitude on daylight availability may have influenced the evolution of migration and photoperiodism. Funct Ecol. 2020;34:1752-66.

41. Denlinger DL. Dormancy in tropical insects. Annu Rev Entomol. 1986;31:239-64

42. Wang $\mathrm{K}$, Sun J, Cheng $\mathrm{G}$, Jiang $\mathrm{H}$. Effect of altitude and latitude on surface air temperature across the Qinghai-Tibet Plateau. J Mt Sci. 2011;8:808-16.

43. Ezeakacha NF, Yee DA. The role of temperature in affecting carry-over effects and larval competition in the globally invasive mosquito Aedes albopictus. Parasites Vectors. 2019;12:1-1.

44. Costa EA, Santos EM, Correia JC, Albuquerque CM. Impact of small variations in temperature and humidity on the reproductive activity and survival of Aedes aegypti (Diptera, Culicidae). Rev Bras Entomol. 2010;54:488-93

45. Edillo FE, Sarcos JR, Sayson SL. Natural vertical transmission of dengue viruses in Aedes aegypti in selected sites in Cebu city. Philippines J Vector Ecol. 2015:40:282-91.

46. Angel $B$, Joshi V. Distribution and seasonality of vertically transmitted dengue viruses in Aedes mosquitoes in arid and semi-arid areas of Rajasthan. India J Vector Borne Dis. 2008;45:56-9.

47. Thongrungkiat S, Maneekan P, Wasinpiyamongkol L, Prummongkol S. Prospective field study of transovarial dengue-virus transmission by two different forms of Aedes aegypti in an urban area of Bangkok. Thailand J Vector Ecol. 2011;36:147-52.

48. Perez MH, Noriega FG. Aedes aegypti pharate 1st instar quiescence affects larval fitness and metal tolerance. J Insect Physiol. 2012;58:824-9.

49. Cruz RVO, Aliño PM, Cabrera OC, David CPC, David LT, Lansigan FP, et al. Philippine climate change assessment: impacts, vulnerabilities, and adaptation. The Oscar M. Lopez Center for Climate Change Adaptation and Disaster Risk Management Foundation, Inc. and Climate Change Commission. Quezon city, Philippines. 2017. ISSN 2508-089X.

50. Chua PL, Dorotan MM, Sigua JA, Estanislao RD, Hashizume M, Salazar MA. Scoping review of climate change and health research in the Philippines: a complementary tool in research Agenda-Setting. Int J Environ Res Public Health. 2019;16:2624.

51. Juliano SA, O'Meara GF, Morrill JR, Cutwa MM. Desiccation and thermal tolerance of eggs and the coexistence of competing mosquitoes. Oecol. 2002;130:458-69.

52. Juliano SA, Philip LL. Ecology of invasive mosquitoes: effects on resident species and on human health. Ecol Lett. 2005;8:558-74.

53. Juliano SA. Species interactions among larval mosquitoes: context dependence across habitat gradients. Annu Rev Entomol. 2009;54:37-56.

54. Rezende GL, Martins AJ, Gentile C, Farnesi LC, Pelajo-Machado M, Peixoto AA, et al. Embryonic desiccation resistance in Aedes aegypti: presumptive role of the chitinized serosal cuticle. BMC Dev Biol. 2008;8:1-4.

55. Urbanski JM, Benoit JB, Michaud MR, Denlinger DL, Armbruster P. The molecular physiology of increased egg desiccation resistance during diapause in the invasive mosquito, Aedes albopictus. Proc Royal Soc B Biol Sci. 2010;277:2683-92.

56. Lewis DJ. Observations on Aëdes aegypti, L. (Dipt. Culic.) under controlled atmospheric conditions. Bull Entomol Res. 1933;24:363-72.

57. Otto M, Neumann RO. Studies of yellow fever in Brazil. J Hyg Infect Dis. 1905;51(1):357-503.

58. Rowley WA, Graham CL. The effect of temperature and relative humidity on the flight performance of female Aedes aegypti. J Insect Physiol. 1968;14:1251-7.

59. Evans ME, Dennehy JJ. Germ banking: bet-hedging and variable release from egg and seed dormancy. Q Rev Biol. 2005;80:431-51.

60. Carrington LB, Armijos MV, Lambrechts L, Barker CM, Scott TW. Effects of fluctuating daily temperatures at critical thermal extremes on Aedes aegypti life-history traits. PLoS ONE. 2013;8:e58824.

61. Bar-Zeev M. The effect of temperature on the growth rate and survival of the immature stages of Aedes aegypti (L.). Bull Entomol Res. 1958;49:157-63.

62. Trpiš M. Dry season survival of Aedes aegypti eggs in various breeding sites in the Dar es Salaam area, Tanzania. Bull World Health Organ. 1972;47:433.
63. Reinhold JM, Lazzari CR, Lahondere C. Effects of the environmental temperature on Aedes aegypti and Aedes albopictus mosquitoes: a Review. Insects. 2018;9:58. https://doi.org/10.3390/insects904015.

64. Gould EA, Higgs S. Impact of climate change and other factors on emerging arbovirus diseases. Trans R Soc Trop Med Hyg. 2009;103:109-21.

65. Jordan RG, Bradshaw WE. Geographic variation in the photoperiodic response of the western tree-hole mosquito Aedes sierrensis. Ann Entomol Soc Am. 1978;71:487-90.

66. Shroyer DA, Craig GB Jr. Egg diapause in Aedes triseriatus (Diptera: Culicidae): geographic variation in photoperiodic response and factors influencing diapause termination. J Med Entomol. 1983;20:601-7.

67. Fitzpatrick C, Haines A, Bangert M, Farlow A, Hemingway J, Velayudhan $R$. An economic evaluation of vector control in the age of a dengue vaccine. PLoS Negl Trop Dis. 2017; 11:e0005785.

\section{Publisher's Note}

Springer Nature remains neutral with regard to jurisdictional claims in published maps and institutional affiliations.
Ready to submit your research? Choose BMC and benefit from:

- fast, convenient online submission

- thorough peer review by experienced researchers in your field

- rapid publication on acceptance

- support for research data, including large and complex data types

- gold Open Access which fosters wider collaboration and increased citations

- maximum visibility for your research: over $100 \mathrm{M}$ website views per year

At BMC, research is always in progress.

Learn more biomedcentral.com/submissions 